\title{
TRANSPORT PROCESSES OF AN IONIC LIQUID IN VARIOUS SOILS
}

\author{
Wojciech Mrozik' \\ Christian Jungnickel ${ }^{2}$ \\ Piotr Stepnowski \\ 'University of Gdansk, Poland \\ ${ }^{2}$ University of Bremen, UFT, Germany \\ ${ }^{3}$ University of Gdansk, Poland
}

\begin{abstract}
Ionic liquids are a new class of chemicals which are finding application in a wide variety of chemical processes. Due to the wide range of possible application in industrial processes, the ionic liquids should be evaluated before they enter the environment. As part of a sustainable development of chemicals, the fate of the chemical needs to be assessed and interactions characterized. Soils form an essential part of this assessment. This study defines and evaluates interaction of an ionic liquid, 1-butyl-3methylimidazolium tetrafluoroborate, with the soil component. This entity was chosen due to its frequent applicability in various organic and catalytic processes and it is likely that it will be soon produced on an industrial scale.

Aim of our work focused on the assessment of the partition coefficients of ionic liquid with different types of saturated soils. The soils used in the experiment were forestry soil, agricultural soil, fluvial agricultural soil, fluvial meadow soil and kaolinite. The partition coefficients were determined using equilibrium batch tests. The influences of other factors such as $\mathrm{pH}$ or ionic strength on sorption dependency of the ionic liquid were also studied.
\end{abstract}

\section{KEYWORDS}

Ionic liquid; Sorption; Distribution coefficient; $\mathrm{pH}$; Ionic strength; Soil environment

\section{INTRODUCTION}

Ionic liquids are a class of compounds which usually consist of an organic cation and a variety of organic or inorganic anions. This allows this class to have a large spectrum of properties, and be synthesised to suit their requirements. These compounds are liquid below $100^{\circ} \mathrm{C}$, and generally have a negligible vapour pressure. They make ideal nonvolatile solvents for a variety of chemical synthesis in industrial scale production [1-3]. Due to their low vapour pressure, they are often classified as safe or 'green' solvents. But 


\author{
Kalmar ECO-TECH 05 and \\ The Second Baltic Symposium on Environmental Chemistry \\ KALMAR, SWEDEN, November 28-30, 2005
}

to fulfil many of the criteria of principles of Green Chemistry according to Anastas [4] more information about the fate assessment of the class of chemicals known as 'ionic liquids' needs to be known. Many of the ionic liquids are water soluble, and even though they may not evaporate, they can still enter the environment to a significant extent through a number of paths. Due to this there is distinct lack of knowledge about their fate assessment and therefore toxicological and ecotoxicological impact [5-7].

Part of the risk assessment of ionic liquids is to determine the interaction of ionic liquids with sediment and soil. This interaction will be defined as an analysis of the sorption process in a number of different soil types. Sorption experiments conducted by Stepnowski [8-10], show that ionic liquid cations sorb quite well to different soil types. However a strong dependency on the structure of the compound is observed. It was shown that the longer the alkyl chain length is on the cation, the higher the sorption coefficient [8].

In this publication a series of experiments are described which analyse the sorption behaviour of 1-butyl-3-methylimidazolium tetrafluoroborate in various soil types under various conditions such as different $\mathrm{pH}$ and ionic strength. The sorption strength of mineral fractions was also under investigation.

\title{
2 MATERIALS AND METHODS
}

\subsection{Chemicals}

The ionic liquid, 1-butyl-3methylimidazolium tetrafluoroborate ([BMIM][BF $]$ ), selected for these studies was obtained from Merck KGaA (Darmstadt, Germany). The ionic liquid was used as obtained, without any additional pre-treatment.

Calcium chloride and sodium hydroxide were obtained from P.P.H "Standard" (Lublin, Poland). Chloride acid 35\%, monopotassium phosphate and ortho-phosphoric acid $85 \%$ used for buffers were purchased from POCh (Gliwice, Poland). Methanol HPLC gradient grade was purchased from Fluka Chemika AG (Buchs, Switzerland) and POCh (Gliwice, Poland).

\subsection{Soils}

Soil used in the experiment: forestry soil (WO), agricultural soil (AGl), fluvial agricultural soil (AG2), fluvial meadow soil (FL) and kaolinite (CL). The surface soils were taken from northern and north-eastern parts of Poland and kaolinite (South Carolina Peerless No. 2) was supplied by R.T.Vanderbilt (USA). Selected properties of these soils are presented in Table 1. The soils were air-dried, ground and sieved. 
Table 1. Characteristic of the soils.

\begin{tabular}{ccccc}
\hline Soil & OCt(\%) & Sand and gravel $(\%)$ & Siltt(\%) & Clay (\%) \\
\hline CL & 0 & 0 & 0 & 100 \\
WO & 3,9 & 4,67 & 59,47 & 35,86 \\
FL & 4,88 & 7,31 & 62,87 & 28,82 \\
AG1 & 4,59 & 5,38 & 36,72 & 57,91 \\
AG2 & 5,49 & 3,57 & 35,93 & 60,5 \\
\hline
\end{tabular}

\subsection{Sorption test}

A batch-equilibrium technique was used to determine the sorption of the ionic liquid. The experiments were performed according to $\mathrm{OECD}$ guidelines [11]. Ionic liquid solutions (5 $\mathrm{ml})$ prepared in $0.01 \mathrm{M} \mathrm{CaCl}_{2}$ were added to the soil $(1 \mathrm{~g})$. Four concentrations $(0.05,0.1$, 0.5 and $1 \mathrm{mM}$ ) were used for all soils and the sediment. The mixtures were shaken for 24 $\mathrm{h}$ and then centrifuged at $5000 \mathrm{rpm}$ for $10 \mathrm{~min}$. The aqueous phase was recovered as completely as possible and the amount of ionic liquid sorbed was determined by direct analysis of the supernatant. All experiments were performed in duplicate. Desorption experiments were performed using aliquots of samples from the sample experiments to which pure $0.01 \mathrm{M}$ calcium chloride $(5 \mathrm{ml})$ was added, and the mixture was shaken for another $24 \mathrm{~h}$. After centrifugation, the desorbed ionic liquid was analyzed directly in the supernatant. The sorption coefficient, $K_{d}$, was calculated as the ratio of the amount of ionic liquid sorbed by the soil to the amount of the analyte in the water at equilibrium. The results of the sorption experiments were additionally evaluated by the Freundlich equation $S=K C^{l / n}$, where $S$ is the amount of ionic liquid sorbed by the soil, $C$ is the concentration of analyte in the water after equilibrium $\left(\mu \mathrm{g} \mathrm{ml} \mathrm{m}^{-t}\right), K_{f}$ is the Freundlich sorption coefficient, and $1 / n$ is the slope of the sorption isotherm.

\subsection{Influence of $\mathbf{p H}$}

The batch-equilibrium technique sorption test for the kaolinite and fluvial soil were used. The $[\mathrm{BMIM}]\left[\mathrm{BF}_{4}\right]$ solution $(1 \mathrm{mM}-5 \mathrm{ml})$ was added to the soil sample $(1 \mathrm{~g})$. In such prepared sample the desired $\mathrm{pH}$ was adjusted with $\mathrm{HCl}$ or $\mathrm{NaOH}$ solutions $(0,5 \mathrm{M})$. The mixture was shaken for $24 \mathrm{~h}$ and afterwards centrifuged at $5000 \mathrm{rpm}$ for $10 \mathrm{~min}$. The aqueous phase was recovered as completely as possible and the amount of ionic liquid sorbed was determined by direct analysis of the supernatant

\subsection{Influence of ionic strength}

The batch-equilibrium technique sorption test for the kaolinite and fluvial soil were used. Four different $\mathrm{CaCl}_{2}$ concentrations $(0.1,0.05,0.005,0.001 \mathrm{M})$ were adjusted in [BMIM] $\left[\mathrm{BF}_{4}\right]$ solution $(1 \mathrm{mM})$. That solution $(5 \mathrm{ml})$ was added to the soil sample $(1 \mathrm{~g})$ and shaken for $24 \mathrm{~h}$ and afterwards centrifuged at $5000 \mathrm{rpm}$ for $10 \mathrm{~min}$. The amount of sorbed ionic liquid was determined by analysis of aqueous phase. 


\author{
Kalmar ECO-TECH '05 and \\ The Second Baltic Symposium on Environmental Chemistry \\ KALMAR, SWEDEN, November 28-30, 2005
}

\title{
2.6 Analysis of ionic liquids
}

The analytical system consisted of an LC 10AT $v p$ metering pump (Shimadzu Ltd.), a syringe loading sample injector (Rheodyne) and a UV/Vis variable wavelength detector (Kontron Instruments). Retention times were recorded with a 3390A HPLC integrator (Hewlett Packard). All separations were performed using a Phenomenex Luna $5 \mu$ SCX $100 \mathrm{~A}$ ion exchange column. The column dimension was $250 \times 4.6 \mathrm{~mm}$ ID. The analyses were performed at ambient temperature at a flow rate of $1.0 \mathrm{ml} \mathrm{min}^{-1}$. The elution profiles were monitored at $220 \mathrm{~nm}$. The separation column was equilibrated with the mobile phase until stabilization of a baseline. Sample injections $(10 \mu \mathrm{l})$ were made at this point. The mobile phase was water-methanol $(65: 35 \mathrm{v} / \mathrm{v})$ mixed with $40 \mathrm{mM}$ phosphate buffer $\left(\mathrm{KH}_{2} \mathrm{PO}_{4} / \mathrm{H}_{3} \mathrm{PO}_{4}\right)$ at $\mathrm{pHt}=3.1[12]$.

\section{RESULTS AND DISCUSSION}

Due to a different type of the soil the strength of the sorption is various. The obtained $\mathrm{K}_{d}$ values differ from $1.8 \mathrm{~cm}^{3} \mathrm{~g}^{-1}$ (kaolinite soil) to $24.1 \mathrm{~cm}^{3} \mathrm{~g}^{-1}$ (fluvial agricultural soil). All distribution coefficients are listed in Table 2. The correlation with the amount of organic carbon content $(\mathrm{OC})$ indicates that interactions of this fraction with the investigated chemical compound plays important role in the sorption process. The higher amount of OC the stronger sorption occurs. However the relatively low $K_{d}$ value for fluvial meadow soil (FL) shows that not only the amount of organic carbon content is important but also type and the quality of it.

Table 2. Distribution coefficient $K_{d .}$ desorption $D$ and Freundlich parameters for [BMIM] $\left[B F_{4}\right]$.

\begin{tabular}{|c|c|c|c|c|c|}
\hline \multirow[t]{2}{*}{ Soil } & \multicolumn{3}{|c|}{$\begin{array}{c}\text { Freundlich Isotherm } \\
\text { Parameters }\end{array}$} & \multirow[t]{2}{*}{$\mathrm{K}_{\mathrm{d}}$} & \multirow[t]{2}{*}{$\mathrm{D}(\%)$} \\
\hline & $K_{f}$ & $I / n$ & $\mathrm{R}^{2}$ & & \\
\hline $\mathrm{CL}$ & 0,23 & 0,96 & 0,98 & 1,8 & 47,1 \\
\hline WO & 1,13 & 0,62 & 0,96 & 2,2 & 54,3 \\
\hline FL & 1,24 & 0,66 & 0,99 & 4,6 & 33,3 \\
\hline AGI & 1,53 & 0,72 & 0,99 & 10,1 & 24,4 \\
\hline AG2 & 1,24 & 1,17 & 0,95 & 24,1 & 9,4 \\
\hline
\end{tabular}

The smaller ratio of oxygen to carbon in humic substances (esp. in humic and fulvic acids) influence the stronger sorption potential [11]. Additionally humic substances can be tied to some clay aggregates which could make their specific interaction sites unavailable for sorption [12]. The amount of the fine fraction in the soil material correlates quite well with the sorption strength. The extent area of fine fraction provides more interaction sites. However more detailed study on AG1 and AG2 soils shows that size fraction have various $\mathrm{K}_{\mathrm{d}}$ values (see Table 3). Especially it is observed in clay minerals. Due the type and structure of clay minerals (illite, montmorillonite or kaolinite) 
Kalmar ECO-TECH '05 and

The Second Baltic Symposium on Environmental Chemistry

KALMAR, SWEDEN, November 28-30, 2005

Table 3. Influence of fraction size on sorption strength $\left(K_{d}\right)$.

\begin{tabular}{ccc}
\hline Size & AG1 & AG2 \\
\hline$<0,1 \mathrm{~mm}$ & 7,2 & 33,2 \\
\hline $0,1-0,25 \mathrm{~mm}$ & 6,9 & 7,2 \\
\hline $0,25-0,5 \mathrm{~mm}$ & 6,8 & 12,2 \\
\hline $0,5-0,8 \mathrm{~mm}$ & 6,2 & 29,0 \\
\hline$>0,8 \mathrm{~mm}$ & 7,3 & 20,7 \\
\hline
\end{tabular}

we can observe different sorption potential. Thus the amount and type of each fraction in investigated soils plays an important role in sorption processes.

Experimental data obtained from the experiment fits with the non-linear Freundlich isotherms well (see Figure l). The slopes of the isotherms $(1 / \mathrm{n})$ are usually below one which can indicate on a concentration dependent sorption and $\mathrm{K}_{\mathrm{f}}$ values also show a good correlation with organic carbon content and $\mathrm{K}_{\mathrm{d}}$ values (see Table 2).

Desorption of $[\mathrm{BMIM}]\left[\mathrm{BF}_{4}\right]$ is dependent on soil type and negatively correlated with the sorption process. The stronger the sorption process the weaker the desorption. From soils with weak binding (e.g. WO) more than $50 \%$ was recovered. While recovery from strong binding soil (AG2) is less than $10 \%$.

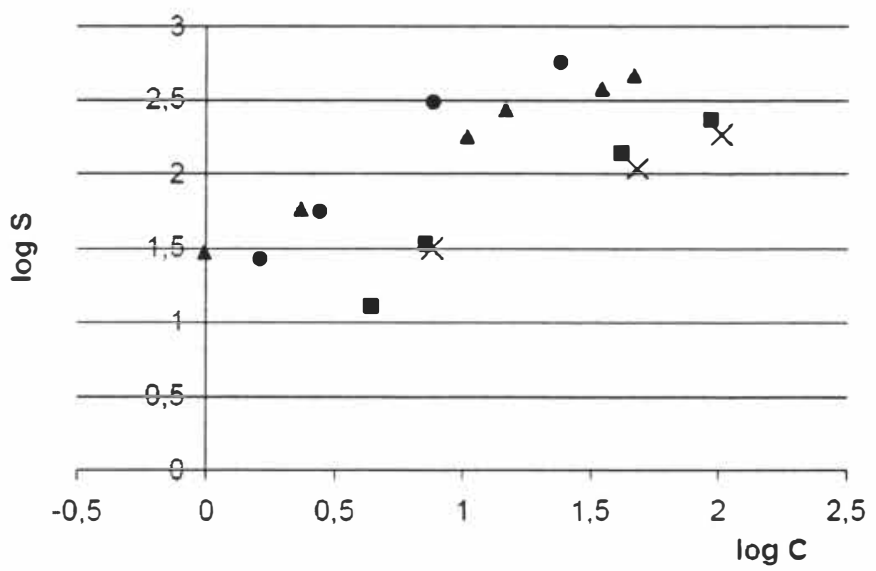

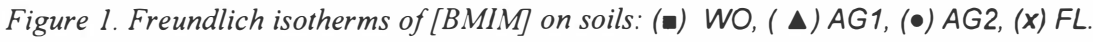


Influence of $\mathrm{pH}$ during sorption process seems to have important role. As expected the higher $\mathrm{pH}$ the stronger the binding. It is caused by large number of negatively charged groups in sorption complexes which are not protonated. Due to that more sites are available for cations of imidazolium salt. Figure 2 shows the change of sorption strength in different $\mathrm{pH}$.

Figure 3 illustrates the relation between sorption coefficients $k_{d}$ and ionic strength of the soil environment. The higher ionic strength, the weaker sorption occurs. The environment with higher salt concentration offers a good ion-pairing for [BMIM] cations. A greater number of calcium ions can compete with cations of the ionic liquid for the negatively charged functional groups on the soil surface. Obtained data shows differences in sorption strength greatly below $0.01 \mathrm{M}$ of calcium chloride, whereas above that value, the change is reduced.

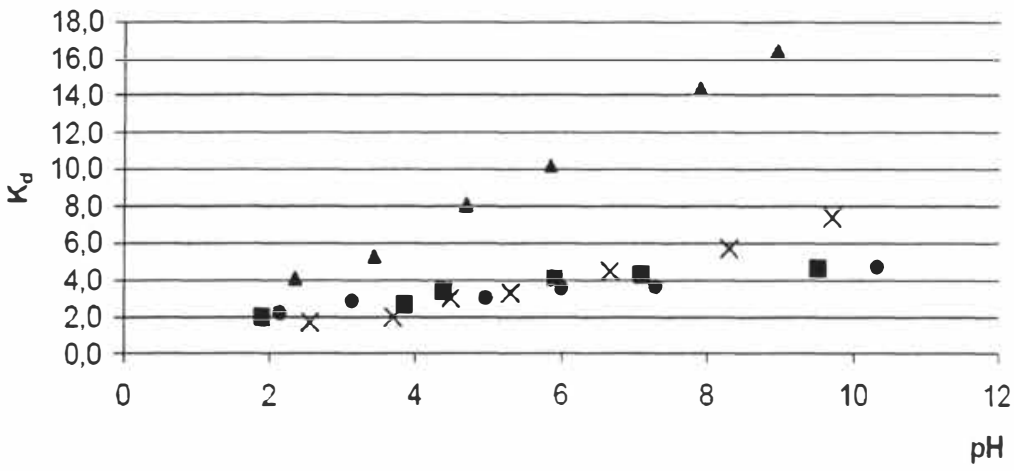

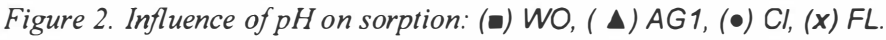

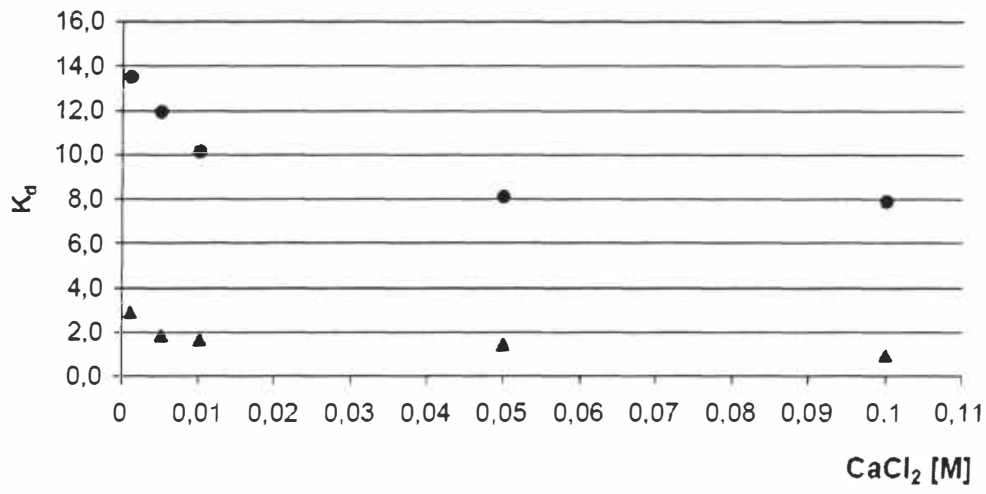

Figure 3. Influence of ionic strength on sorption. 


\section{CONCLUSIONS}

The results obtained from these experiments indicate that the strength of the sorption of $[\mathrm{BMIM}]\left[\mathrm{BF}_{4}\right]$ is strongly correlated to the type of soil. It seems that the main role in the sorption process is played by organic substances which are included in the soil components. Possibility of various interactions such as ionic, dispersive or $\Pi$ - $\Pi$, make the role of organic fraction in sorption process significant. However the type and quality of humic substances (e.g. more humic acid than fulvic acid) and OC ratio, which are correlated to that, could influence the sorption strength. Further experiments with pure humic substances should be investigated further. The fraction diversity and especially the type and the amount of the clay mineral can assume some responsibility in the sorption process. Due to their structure, clay minerals possess different possibilities with which to interact with chemical compounds. Experiments with some different clay mineral such as montmorillonite or illite should be investigated. The influence of $\mathrm{pH}$ is also noticeable, however not as much as the other factors. The $\mathrm{pH}$ is strongly connected to the surface charge of the soil environment. By altering the $\mathrm{pH}$ it is possible to protonate or deprotonate functional groups in humics or the charge in clay minerals. The ionic strength has some influence on sorption in lower concentration of salt. In higher concentration is not so evident.

Future research should also include a larger diversity of ionic liquids such as other imidazolium, piridynium or phosphonium salts

\section{ACKNOWLEDGEMENTS}

Financial support was provided by the Polish Ministry of Scientific Research and Information Technology under grants: 2P04G08329 and 2P04G1 1829.

\section{REFERENCES}

[1] Sheldon, R., 2001. Catalytic reactions in ionic liquids. Chem Comunn (23), 23992407.

[2] Sheldon, R. A., Lau, R. M., Sorgedrager, F., van Rantwijk, K., Seddon, R., 2002. Biocatalysis in ionic liquids. Green Chem. 4, 147-151.

[3] Wasserscheid, P., van Hal R., Bösmann, A., 2002. 1-n-Butyl-3-methylimidazolium ([bmim]) octylsulfate - an even 'greener' ionic liquid. Green Chemistry 4: 400-404.

[4] Anastas, P. A., Warner, J. C., 1998. Green Chemistry: Theory and Practice. Oxford University Press, Oxford.

[5] Jastorff, B., Störmann, R., Ranke, J., Mölter, K., Stock, F., Oberheitmann, B., Hoffmann, W., Hoffmann, J., Nuchter, M., Ondruschka B., Filser,J., 2003. How hazardous are ionic liquids? Structure-activity relationships and biological testing as important elements for sustainability evaluation. Green Chemistry 5 (2), 136-1t42.

[6] MacFarlane, D. R., 2004. Ionic Liquids Symposium. Aust. J. Chem 57, 111-112.

[7] Wilkes, J. S., 2004. Properties of ionic liquid solvents for catalysis. Mol. Catal. AChem 214, 11-17. 
[8] Stepnowski, P.,2005. Preliminary assessment of the sorption of some alkyl imidazolium cations as used in ionic liquids to soils and sediments. Aust. J. Chem. $58,170-1773$.

[9] Stepnowski, P., Mrozik W., Jungnickel, C.. 2005. Behaviour of BMIMBF4 ionic liquid in selected saturated soils. In: Proceedings of the 4th International Conference Oils and Environment, Gdansk, Poland.

[10] Stepnowski, P., Mrozik, W., Jungnickel, C., 2005. Distribution of ionic liquids in soils. In: Proceedings of the 10th EuCheMS Conference on Chemistry and the Environment, Rimini, Italy.

[11] OECD, 2000. Adsorption - Desorption Using a Batch Equilibrium Method. OECD guideline for testing of chemicals, p. 106.

[12] Stepnowski P., Mrozik W., 2005. Analysis of selected ionic liquid cations by ion exchange chromatography and reversed-phase high performance liquid chromatography. J. Sep. Sci. 28, 149-154.

[13] Huang W., Peng P., Yu Z., Fu J. 2003. Effects of organic matter heterogeneity on sorption and desorption of organic contaminants by soils and sediments. Applied Geochemistry 18, 955-972.

[14] Spark K.M., Swift R.S., 2002. Effect of soil composition and dissolved organic matter on pesticide sorption. The Science of the Total Environment 298, 147-161. 